\title{
EDITORIAL
}

\section{Reduced smoking - an acceptable goal for the hopeless heavy smoker?}

\author{
H.H. Klech
}

Smoking represents today by far the largest preventable cause of death. Data suggest annual premature deaths of 420,000 smokers [1] and of 53,000 passive smokers [2, 3] in the USA alone. A necessary step in the reduction of the smoking epidemic is the use of educational prevention programmes for those at risk of starting smoking, and initiatives to promote smoking cessation for smokers. Although there is no doubt about the clear long-term benefit of smoking cessation, both for the smoker as well as for the healthcare provider particularly as regards cancer and chronic obstructive pulmonary disease (COPD), comparatively little is known about the substantial short-term health and economic benefits of smoking cessation. The excess risk of myocardial infarction or stroke decreases by approximately $50 \%$ within the first year after stopping smoking [4].

Strategies for smoking cessation programmes are well known today and widely used. Nicotine replacement therapy remains the core of each strategy, particularly for nicotine-dependent heavy smokers (smoking >20 cigarettes. day $\left.^{-1}\right)$. Sustained quit rates (6 months and 1 yr success rates) are more frequent among light to moderate smokers compared to heavy smokers $[5,6]$. Thus, relapse rates in heavy smokers are less favourable. The reasons are in most cases obvious:

1) Withdrawal symptoms in heavy smokers are more prominent mostly due to nicotine dependency.

2) Smoking cessation among heavy smokers usually requires a higher amount of willingness to change current behaviour and life style.

3) Co-existence of addictive dependencies such as alcoholism or even abuse of narcotic drugs is more often seen in heavy smokers. Recent data suggest that smoking diminishes the subjective perception of alcohol intoxication [7]. Development of Dupuytren's contracture is strongly related to alcoholism and to heavy smoking [8]. Smokers with alcohol problems undergoing cessation therapy with nicotine patches showed a significantly lower 1 yr quit rate (close to placebo) when compared to nonalcoholic smokers [9]. Thus, focusing only on smoking cessation without also addressing alcohol or drug dependence has a higher risk of failure.

4) Concerns of smokers regarding weight gain after smoking cessation is one of the most intriguing obstacles, particularly in female patients [10-12]. Recent data confirm the significant correlation between smoking and lower body mass index (BMI). Inversely, a higher relative body weight is found with smoking cessation [13].

5) Heavy smokers most often need a tailored nicotine replacement strategy. Current available nicotine delivery systems (gum, patch, nasal spray, inhalation, etc.) are not

Correspondence: H.H. Klech, Apollogasse 8, A-1070 Vienna, Austria. Fax: 43171178613 always adequately used or differences among the various nicotine replacement preparations not fully recognized [14]. Use of too low doses and/or an inappropriate choice of nicotine delivery system seem to be the most frequent cause of failure among heavy smokers $[14,15]$. A more "intelligent" use of nicotine preparations is required, which fits the individual use and demands of the heavy smoker ("Nicotine replacement science").

6) Smoking cessation therapies and help to cease smoking should be more intensively offered to heavy smokers by institutions where smokers are hospitalized or acutely treated due to tobacco-associated diseases such as myocardial infarction, peripheral angiopathy, COPD etc.

7) Heavy smokers who repeatedly fail to quit are at risk of considering themselves hopeless smokers, which contributes to their despair and their unwillingness for another attempt. Very little is known about continuing attempts of smoking cessation in this group of repeatedly relapsed smokers [16].

However, what alternatives are there today for the heavy smoker who repeatedly fails to quit, who does not believe that he will overcome his habit or his nicotine dependency but wants to reduce his risk?

1) Switching to light or ultralight cigarettes is heavily advertised by the tobacco industry as a reasonable means to reduce the health risk of cigarette smoking. Current evidence, however, does not suggest that by smoking light cigarettes (nicotine level $<1.0 \mathrm{mg}$ and tar level $<10 \mathrm{mg}$ ) the health risk is significantly reduced, particularly not the cardiovascular risk $[17,18]$, because smokers usually compensate by changing their smoking patterns and behaviours when switching to light cigarettes [19-21]. Additionally, there are no long-term data available which could better establish the potential benefits of switching to light cigarettes [22]. Ultralight cigarettes which could potentially reduce the tar and $\mathrm{CO}$ burden of the smoker are generally not well accepted by heavy smokers as an alternative [23]. 2) Some cigarette smokers switch to pipe or cigar smoking in the hope that this will reduce their risk. Most recent data [24] confirm that this behaviour reduces the overall amount of tobacco consumption for the smoker by $>50 \%$. Consequently, the overall risk of death in pipe or cigar smokers who switched from cigarette smoking 20 yrs ago is reduced by $46 \%$ compared to continuing smokers. However, a switch from cigarettes to pipe or cigars still showed a $51 \%$ higher risk of death compared to pipe or cigar smokers who have never smoked cigarettes before, because former cigarette smokers usually continue to inhale the smoke even when they are smoking from pipes or cigars, demonstrated by their higher carboxyhaemoglobin saturation [24].

3) The concept of "Reduced smoking" is proposed in this issue of the European Respiratory Journal by JIMÉNEZ-RUIZ et al. [25]. This concept acknowledges the obvious inabil- 
ity of a defined group of heavy smokers largely dependent on and addicted to nicotine to entirely quit smoking. They suggest that in this group of nicotine-dependent smokers with unsuccessful attempts at smoking cessation, the goal of a nicotine replacement might be modified. Rather than aiming for complete cessation with a high probability of failure they would use nicotine replacement only to gradually reduce the daily number of cigarettes smoked. This would lead to a reduced intake of toxic substances and therefore a lower impact on tobacco-related diseases. JiMÉNEZ-Ruz et al. [25] are suggesting that this concept be applied to individuals who: 1) are failing in cessation attempts; 2) want to quit but are unable to do so; 3) do not want to quit but want to reduce smoking. They express hope that individuals who succeeded in reducing their cigarette smoking may later on find it easier to achieve the ultimate goal of entire cessation.

The concept of reduced smoking is very pragmatic. It is based on evidence that there is a dose-dependent risk of smoking in tobacco-related diseases such as cancer, COPD, various cardiovascular diseases and for problems during pregnancy. Only very few studies are available to better quantify the impact of reduced smoking: 1) a decrease of indicators of inflammation in the bronchial mucosa is evidenced by bronchoscopy and bronchoalveolar lavage [26], and a significant decrease of saturated carboxyhaemoglobin can be observed [27]; 2) no long-term clinical studies are so far available; 3) the risk of double nicotine intake (nicotine from smoking and from nicotine replacement) has been probably overemphasized in the past. Data from a $5 \mathrm{yr}$ study showed that individuals taking nicotine gums and who continued smoking did not experience more cardiovascular events compared to a group who took the gum without further smoking [28].

The concept of "reduced smoking" as an alternative goal for the heavy smoker who cannot quit, presented by JIMÉNEZ-RUIZ et al. [25] is simple and pragmatic. It may be a valuable tool to address the frustration of patients and therapists in the appropriate clinical setting of heavy smok-ers. It will alter some of the paradigms and therapy goals of nicotine replacement and smoking cessation therapy. More long-term studies are necessary to better evaluate the clinical and economic value of such an approach.

\section{References}

1. Reducing the Health Consequences of Smoking: 25 Years of Progress. Atlanta, GA: Centers for Disease Control, Center for Chronic Disease Prevention and Health Promotion, Office on Smoking and Health; US Department of Health and Human Services publication CDC 89-8411, 1989.

2. Glantz SA, Parmley WW. Passive smoking and heart disease: epidemiology, physiology and biochemistry. Circulation 1988; 83: 1-12.

3. Wells AJ. An estimate of adult mortality in the United States from passive smoking. Environ Int 1988; 14: 249-265.

4. Lightwood JM, Stanton A, Glantz A. Short-term economic and health benefits of smoking cessation. Myocardial infarction and stroke. Circulation 1997; 96; 4: 1089-1096.

5. Jarvis MJ. A profile of tobacco smoking. Addiction 1994; 89: 1371-1376.

6. Jarvis MJ. Smoking cessation. Eur Respir Rev 1997; 7; 45: 230-234.

7. Madden PA, Heath AC, Starmer GA, Whitfield JB, Martin NG. Alcohol sensitivity and smoking history in men and women. Alcohol Clin Exp Res 1995; 19: 1111-1120.

8. Burge P, Hoy G, Regan P, Milne R. Smoking, alcohol and the risk of Dupuytren's contracture. J Bone Joint Surg Br 1997; 79: 206-210.

9. Hurt RD, Dale LC, Offord KP, Croghan IT, Hays JT, Gomez-Dahl L. Nicotine patch therapy for smoking cessation in recovering alcoholics. Addiction 1995; 90: 15411546.

10. Perkins KA, Epstein LH Sexton JE, Solberg-Kassel R, Stiller RL, Jacob RG. Effects of nicotine on hunger and eating in male and female smokers. Psychopharmacology 1992; 106: 53-59.

11. Perkins KA, Epstein LH, Stiller RL, et al. Acute effects of nicotine on hunger and caloric intake in smokers and nonsmokers. Psychopharmacology 1991; 103: 103-109.

12. Schmeiser-Rieder A, Schoberberger R, Kunze M. Frauen und Rauchen. Wien Med Wochenschr 1995; 145: 73-76.

13. Rasky E, Stronegger WJ, Freidl W. The relationship between bodyweight and patterns of smoking in women and men. Int J Epidemiol 1996; 25: 1208-1212.

14. Benowitz NL, Zevin S, Jacob III P. Sources of variability in nicotine and cotine levels with use of nicotine nasal spray, transdermal nicotine, and cigarette smoking. $\mathrm{Br} \mathrm{J}$ Clin Pharmacol 1997; 43/3: 259-267.

15. Tonnesen P, Mikkelsen K, Norregaard J, Jorgensen S. Recycling of hard core smokers with nicotine nasal spray. Eur Respir J 1996; 9: 1619-1623.

16. Gourlay SG, Forbes A, Marriner T, Pethica D, McNeil JJ. Double blind trial of repeated treatment with transdermal nicotine for relapsed smokers. BMJ 1995; 311: 363-366.

17. Kaufmann DW, Helmrich SP, Rosenberg L, Muttman OS, Shapiro S. Nicotine and carbon monoxide contest of cigarette smoke and the risk of myocardial infarction in young men. N Engl J Med 1983; 308: 409-413.

18. Palmer JR, Rosenberg L, Shapiro S. Low-yield cigarettes and the risk of nonfatal myocardial infarction in women. N Engl J Med 1989; 320: 1569-1573.

19. Kolonen S, Tuomisto J, Puustinen P, Airaksinen MM. Smoking behaviour in low-yield cigarette smokers and switchers in the natural environmental. Pharmacol Biochem Behav 1988; 40: 177-180.

20. Weinhold LL, Stitzer ML. Effect of puffnumber and puffspacing on carbon monoxide exposure from commercial brand cigarettes. Pharmacol Biochem Behav 1988; 33: 853-858.

21. Woodman G, Newman SP, Pavia D, Clarke W. Inhaled smoke volume and puffindices with cigarettes of different tar and nicotine levels. Eur J Respir Dis 1987; 70: 187192.

22. Klech H. Verringern Leichtzigaretten das Risiko des Zigarettenrauchens? Wien Med Wochenschr 1994; 144: 573-576.

23. Kozlowski LT. Evidence for limits on the acceptability of lowest tar cigarettes. Am J Public Health 1989; 79: 198-199.

24. Wald NJ, Watt HC. Prospective study of effect of switching from cigarettes to pipes or cigars on mortality from three smoking related diseases. BMJ 1997; 314: 1860-1863.

25. Jiménez-Ruiz C, Kunze M, Fagerström KO. Nicotine replacement: a new approach to reducing tobacco-related harm. Eur Respir J 1998; 11: 473-479.

26. Rennard S, Daughton D, Fujita J, et al. Short term smoking reduction is associated with reduction in measures of lower respiratory tract inflammation in heavy smokers. Eur Respir J 1990; 3: 752-759.

27. Fagerstroem KO, Tejding R, Westin A, Lunnell E. Aiding reduction of smoking with nicotine replacement medications. A strategy for the hopeless? Eur Respir J 1996; 9: Suppl. 23, 170s.

28. Murray RP, Bailey W, Daniels K, et al. Safety of nicotine polacrilex gum used by 3094 participants in the Lung Health Study. Chest 1996; 109: 438-445. 